\title{
Practice-based Research Networks (PBRNs): Meeting the Challenges of the Future
}

\author{
Walter L. Calmbach MD, MPH, John G. Ryan, DrPH, Laura-Mae Baldwin, MD, MPH, \\ and Lyndee Knox, PhD
}

Practice-based research networks (PBRNs) are useful tools for conducting studies in the busy primary care setting, but their continued existence is threatened by a range of challenges. PBRNs must position themselves now to be prepared to face the challenges ahead. For example, experience with the Clinical Translational Science Awards has placed PBRNs at the center of university efforts toward greater community engagement. Networks must use this opportunity to solicit infrastructure support and partner with experienced principal investigators from other disciplines. Successful networks must make greater use of health information technology to solicit clinician involvement, identify and recruit potential subjects, and disseminate key findings. To maintain the active participation of busy clinicians in the clinical research enterprise, networks must find new ways to engage their members and simplify study participation. Networks should pursue clinically relevant projects that create meaning and connect busy practitioners to the larger agenda of primary care research. Finally, collaborating with other networks in a structured and ongoing manner is one way for PBRNs to extend their reach while making maximal use of their unique resources and local expertise. (J Am Board Fam Med 2012;25:572-576.)

Keywords: Health Information Technology, Practice-based Research, Practice-based Research Networks, Primary Health Care

Although practice-based research networks (PBRNs) are useful tools for conducting practice-relevant research in the busy primary care setting, their existence is threatened by a range of challenges. Busy clinicians struggle with daily practice concerns, while practicebased research faces ever more stringent oversight and restrictions. Funding streams are tight, and many networks face a shortage of experienced principal investigators. This article aims to explore sev-

This article was externally peer reviewed.

Submitted 2 March 2012; revised 3 July 2012; accepted 9 July 2012.

From the Department of Family and Community Medicine, University of Texas Health Science Center, San Antonio (WLC); the Department of Family Medicine and Community Health, Leonard M. Miller School of Medicine, University of Miami, Miami, FL (JGR); the Department of Family Medicine, University of Washington, Seattle (L$\mathrm{MB}$ ); and LA Net, Long Beach, CA (LK).

Funding: none.

Conflict of interest: none declared.

Corresponding author: Walter L. Calmbach, MD, MPH, Department of Family and Community Medicine, University of Texas Health Science Center, San Antonio, 7703 Floyd Curl Dr, Mailcode 7795, San Antonio, TX 78229 3900(E-mail calmbach@uthscsa.edu). eral methods for existing PBRNs to meet the challenges of the future, specifically, working more closely with academic institutions, making greater use of health information technology (HIT), finding new ways to recruit and retain busy clinicians, and developing consortia of successful PBRNs.

\section{Universities and PBRNs}

The advent of Clinical Translational Science Awards (CTSAs) on many university campuses presents both opportunities and challenges for PBRNs. ${ }^{1,2}$ CTSAs may benefit PBRNs in that they offer university support and increased visibility, ${ }^{2}$ but they also could be detrimental if the university tries to impose a top-down research agenda onto already busy primary care physicians.

The collaboration of PBRNs with CTSAs is a process that still is developing, so PBRNs must actively help the university understand the true financial costs of creating and maintaining working relationships with community clinicians and practices. ${ }^{3}$ At the same time, clinicians are interested in university-sponsored educational activities, continu- 
ing medical education, and a sense of being connected to the university. ${ }^{2,4}$ Thus, connectivity and mutual education are vitally important to both groups.

PBRNs should actively promote communication with their associated universities. For example, academic investigators may not realize that research projects are reviewed by network leadership and staff, as well as by physician members of the network, and that not all proposals will be approved. Having university researchers present ideas to a network planning meeting or proposal review session would allow them to meet with network staff and establish relationships with member clinicians. PBRNs should help their university colleagues understand member clinicians' research priorities and the practical limits for research in the busy practice setting.

Successful relationships between universities and PBRNs are built on respect for member clinicians. Community clinicians may not be responsive to an imposed research agenda or to research that impacts their busy day-to-day practices. Networks can facilitate these respectful relationships by listening to their members, fostering 2-way communication, and allowing clinicians to opt out of projects when necessary. Networks also can ensure that academic investigators work through network leadership and staff to ensure a "small footprint" on participating sites.

Another area that can promote collaboration between PBRNs and universities is in the implementation of HIT. PBRNs can mobilize university resources to help member practices adopt the best electronic health record (EHR) for their sites and implement elements of the patient-centered medical home. At a time when busy practices are struggling to qualify for "meaningful use" criteria and pay-for-performance initiatives, PBRNs can provide added value to their member practices by helping them address these important but time-consuming issues.

\section{Health Information Technology and PBRNs}

PBRNs face many challenges when conducting clinically relevant research, often with limited resources across complex, geographically distant, and diverse clinics and health systems. HIT tools for clinical practice, built primarily to improve the quality and efficiency of patient care, provide exceptional opportunities to support and foster this research with greater efficiency at lower cost.
EHRs offer a valuable infrastructure for data on health status, clinical management, and patient outcomes. However, the opportunities and challenges of conducting research using HIT tools in the busy practice setting can be difficult for researchers and clinicians alike.

PBRN researchers recognize the potential of practice EHRs and are developing IT systems and software tools to facilitate their use in practicebased research. EHRs can provide PBRNs with efficient, economical identification of potential research participants, recruitment of practices and participants to research, and collection of large volumes of standardized data across a wide range of practices and clinics. ${ }^{5-7}$

IT tools (eg, clinical decision support tools) also are being used as interventions for practice-based research. ${ }^{8}$ Similarly, tablet PCs or desktop kiosks in practice waiting rooms give practices the ability to conduct individualized health assessments and tailored educational interventions., ${ }^{9,10}$

IT tools also can provide a technical architecture that allows PBRNs with different types of EHRs the ability to link data and develop IT-based research functions across multiple practices. The Distributed Ambulatory Research and Therapeutics Network (DARTNet) uses this type of "federated" architecture. ${ }^{11,12}$ One benefit of these HIT tools is their ability to serve both the clinician and the researcher. EHRs designed to maintain a record of clinical care offer a wealth of research-ready data, and IT tools designed for research offer enhancements to a clinical practice. These tools can benefit participating clinicians by helping them implement elements of the patient-centered medical home, qualify for pay-for-performance incentives, and meet "meaningful use" criteria. This synergy between IT-enhanced research and clinical practice can strengthen the productive relationship PBRNs have with their members, enhancing recruitment and retention of busy clinicians.

\section{Recruiting and Retaining Clinicians}

PBRNs depend on their ability to recruit and retain busy clinicians as active members. The network's ability to generate new knowledge, translate research findings into daily practice, and implement policy guidelines depends on the drive and commitment of member clinicians. A carefully crafted recruitment approach is key to network success, 
and these recruitment strategies must be tailored to the local health care environment. ${ }^{4}$ Networks that make PBRN participation both feasible and compelling are more likely to succeed in recruiting and retaining clinicians and their practices. ${ }^{13}$

Many primary care practices are overwhelmed with unfunded tasks: adopting EHRs, meeting "meaningful use" criteria, forming accountable care organizations, and implementing the patient-centered medical home. These competing demands prevent practices from joining PBRNs or participating in studies. ${ }^{14}$ At the same time, these challenges present an opportunity for networks to serve as a resource to their member practices. The expertise that PBRNs offer is directly relevant to quality improvement and can support activities such as implementation of the patient-centered medical home, uptake of evidence-based guidelines, and adoption of best practices. ${ }^{15}$ Helping practices adopt an EHR provides an excellent opportunity to introduce enhanced processes of care and to create report templates that support both quality improvement and discovery/research.

Considering the many pressures facing clinicians and practices in today's medical marketplace, PBRNs must add real value to their member practices. To the extent that PBRNs provide real resources to practices, participation in PBRNs will be seen as desirable by clinicians and managers alike. Such resources may include practice facilitators who can support both research and quality improvement and generate actionable data that practices can use for quality improvement, pay-forperformance, or strategic planning. ${ }^{16}$

There are a number of specific strategies for recruiting and retaining network clinicians and practices to PBRNs. First and foremost, busy practitioners often join because they know other clinicians in the network. Some PBRNs are experimenting with social media as a means to build interest and communicate with members. Simple ideas such as E-mail list servers are efficient ways to share information and boost recruitment. Another strategy is "recruiting by convening": the network's annual convocation is an excellent opportunity to increase visibility, attract new participants, and reengage current members. PBRNs also can foster a sense of community and increase awareness through E-newsletters, network web sites, and press releases. Finally, there is "recruitment through participation," using a currently funded study to galvanize interest in the network.

\section{Multinetwork Collaborations}

PBRNs can survive and even thrive in challenging situations by working with other experienced networks in a structured and ongoing manner. Such consortia of networks are taking shape, as demonstrated by the Agency for Healthcare Research and Quality Task Order process, the multiple partnerships created by the American Academy of Family Physicians National Research Network, and the ongoing collaboration that underpins the Primary Care Multiethnic Network (PRIME-Net). ${ }^{17,18}$ By working together in this way, groups of PBRNs can demonstrate a broader scope, a depth of experience, and a range of capabilities. With a wider array of clinicians and patients, such consortia of networks can enhance the generalizability of their findings and increase the range of stakeholders that would be interested in their projects. In this way, PBRNs can leverage their existing resources and become more attractive research engines for potential funders.

Any network contemplating such a partnership should learn from the experience of established network consortia. ${ }^{19}$ One key to success is a shared sense of mission and a common vision of the group's goals. Organizing such a consortium requires processes for shared decision making, prioritization of research agendas and goals, and focus of disparate members on detailed planning for collaborative projects. Experienced partnerships emphasize the importance of having cross-network policies and structures in place before the start of any group project. IT is crucial to the development of these often widely dispersed working groups. As decisions are made and processes are put in place, it is important that win-win solutions be found and implemented. ${ }^{19}$

When building such a consortium, an important initial focus is creating a central infrastructure that supports ongoing collaboration. Shared leadership is key to the continued success of such a partnership, but local and central champions who concur with the rationale of the consortium are also critical to its success. The consortium should plan for a separation of responsibilities: a central director who convenes meetings and coordinates activities, and a primary investigator 
for each project who takes responsibility for implementation and completion. Finally, the rationale for the consortium must be refined constantly so that it appeals to crucial stakeholders (ie, clinicians, patients, community organizations, universities, and funders).

\section{Conclusions}

Looking ahead, if PBRNs work more closely with their sponsoring or home institutions, they can benefit from the research expertise and financial support they offer and facilitate mutually beneficial and respectful academic-practice partnerships. Networks that make more sophisticated use of HIT can maximize their research capabilities in difficult economic times. Networks that employ a wide range of recruitment techniques and focus on clinically relevant research questions will engage and motivate their members. Because of their close relationship with practitioners, PBRNs are in a unique position to create meaning with carefully selected projects that connect busy practitioners to the larger primary care research agenda. Last, established networks that join or create a consortium of PBRNs can build on local strengths while reducing the workload on any individual network member. In these ways, PBRNs can meet the challenging environment facing them today.

The authors acknowledge the contribution of several experienced PBRN researchers to the content and ideas of this manuscript, notably Wilson D. Pace, MD MPH (AAFP National Research Network); Lyle J. Fagnan, MD MPH (Oregon Rural PBRN); and Robert L. Williams, MD MPH (RIOS Net and PRIME-Net).

\section{References}

1. Neale AV, Bowman MA. Fourth Journal of the American Board of Family Medicine practice-based research theme issue. J Am Board Fam Med 2009; 22:343-5.

2. Fagnan LJ, Davis M, Deyo RA, Werner JJ, Stange KC. Linking practice-based research networks and Clinical and Translational Science Awards: new opportunities for community engagement by academic health centers. Acad Med 2010;85:476-83.

3. Green LA, White LL, Barry HC, Nease DE Jr, Hudson BL. Infrastructure requirements for practice-based research networks. Ann Fam Med 2005; 3(Suppl 1):S5-11.

4. Bakken S, Lantigua RA, Busacca LV, Bigger JT. Barriers enablers and incentives for research par- ticipation: a report from the Ambulatory Care Research Network J Am Board Fam Med 2009;22: 436-45.

5. Tierney WM, Oppenheimer CC, Hudson BL, et al. A national survey of primary care practicebased research networks. Ann Fam Med 2007;5: 242-50.

6. Weiner MG, Lyman JA, Murphy M. Electronic health records: high-quality electronic data for higher-quality clinical research. Inform Prim Care 2007; 15:121-7.

7. Pace WD, Staton EW. Electronic data collection options for practice-based research networks. Ann Fam Med 2005;3(Suppl 1):S21-9.

8. Johnston ME, Langton KB, Haynes RB, Mathieu A. Effects of computer-based clinical decision support systems on clinician performance and patient outcome. A critical appraisal of research. Ann Intern Med 1994;120:135-42.

9. Joshi A, Weng W, Lichenstein R, Arora M, Sears A. Prospective tracking of a pediatric emergency department e-kiosk to deliver asthma education. Health Informatics J 2009;15:282-95.

10. Pendleton BF, Labuda Schrop S, Ritter C, et al. Underserved patients' choice of kiosk-based preventive health information. Fam Med 2010;42: 488-95.

11. Pace WD, Cifuentes M, Valuck RJ, Staton EW, Brandt EC, West DR. An electronic practicebased network for observational comparative effectiveness research. Ann Intern Med 2009;151: $338-40$.

12. Libby AM, Pace W, Bryan C, et al. Comparative effectiveness research in DARTNet primary care practices: point of care data collection on hypoglycemia and over-the-counter and herbal use among patients diagnosed with diabetes. Med Care 2010; 48(6 Suppl):S39-44.

13. Fagnan LJ, Handley MA, Rollins N, Mold J. Voices from left of the dial: reflections of practicebased researchers. J Am Board Fam Med 2010;23: 442-51.

14. Gibson K, Szilagyi P, Swanger CM, et al. Physician perspectives on incentives to participate in practicebased research: a Greater Rochester Practice-Based Research Network (GR-PBRN) study. J Am Board Fam Med 2010;23:452-4.

15. Mold JA, Peterson KA. Primary care practice-based research networks: working at the interface between research and quality. Ann Fam Med 2005;3(Suppl 1):S12-20.

16. Nagykaldi Z, Mold JW, Robinson A, Niebauer L, Ford A. Practice facilitators and practice-based research networks. J Am Board Fam Med 2006;19: 506-10.

17. Graham DG, Spano MS, Stewart TV, Staton EW, Meers A, Pace WD. Strategies for planning and launching PBRN research studies: a project of the 
Academy of Family Physicians National Research Network (AAFP NRN). J Am Board Fam Med 2007; 20:220-8.

18. Williams RL, McPherson L, Kong A, Skipper B, Weller N; PRIME-Net clinicians. Internet-based training in a practice based research network consortium: a report from the Primary Care Multi-
Ethnic Network (PRIME-Net). J Am Board Fam Med 2009;22:446-52.

19. Williams RL, Johnson SB, Greene SM, et al. Signposts along the NIH roadmap for reengineering clinical research: lessons from the Clinical Research Networks Initiative. Arch Intern Med 2008;168: 1919-25. 